\title{
Déjà vu and the Timequake: Beyond Postmodernism
}

\author{
FEDERICO GIORDANO, University for Foreigners, Perugia
}

\begin{abstract}
The aim of this article is to verify how Tony Scott proved to be, throughout his career, a director particularly sensitive to social shifts and to artistic and cultural modifications. He adjusted the content and formal structure of his films according to what seemed to be the most "modern" or suitable way of depicting contemporaneity. When observed in these terms and a posteriori, in his last films Tony Scott can be seen as a director who tried to go beyond postmodernism, addressing himself towards the new movements of post-postmodernism, as with metamodernism, pseudomodernism or digimodernism. Among Scott's films, the one which seems to be particularly relevant in this sense is Déjà $V u$ (2006), where the latest artistic point of view of the director is quite well summarized. It is a film that puts into metaphor some of the political problems of our epoch and, above all, through a reflection on time embraces some of the features of postmodernism. In doing so, it surpasses postmodernism, opening towards the new aesthetic movement of post-postmodernism. In such a kind of filmic construction, which entails a theoretical reflection on modernity through images, Scott adopts and confirms the post-postmodernist inclination of the final phase of his body of work.
\end{abstract}

\section{KEYWORDS}

Postmodernism, digimodernism, metamodernism, pseudomodernism, alternative worlds.

\section{Fluidity, epigonal films and adherence to the spirit of the times}

In referring to Tony Scott's filmography and reconsidering his later works in an attempt to grasp the distinctive elements of director, both themes as well as stylistic variables that run throughout his work can be pinpointed. Yet, if in conjunction with these objective findings an attempt were made to outline a complex definition which takes a general interpretive approach rather than an analytical one - an approach, by definition, bound to form and nevertheless influenced by the preference of each critic - we might struggle to come up with an answer. Particularly bearing in mind the reception of Scott's works and the extent of their influence on the collective imagination (not only the American one), certain considerations can be made which will help realise this summary. Tony Scott's films always seem to be in touch with the widest of public tastes and even the smallest circle or most knowledgeable audience, including the critics, find in his works some traits of interest (see Gerosa 2014, 3549). Nevertheless, even at the peak of his career, Scott's films seem to lack something. Consequently, they were never acknowledged as part of the works representing the aesthetic 
height of their times. They neither seem to have become representative or emblematic of popular passion, nor have they defined an age of cinema supported by his audience, apart from Top Gun (1986). However, even if Tony Scott's films are not usually considered to be the best reflection of their times, those that define par excellence the precepts, aesthetics and imaginary problems of the age always appear to hold something back. Tony Scott's films absorb the spirit of the times even though they are never the main pivots (see ZC 2007).

Tony Scott's films always appear to be followers of a fashion: they are not films which primarily describe the times in the collective, aesthetic or socio-political imagination, but they do echo some parts of it, making them unconsciously receptive. In the film Loving Memory (1971), for instance, we grasp the difficult elaboration of the European trauma of the Second World War. In The Hunger (1983), the course of events of the 1980s is fully captured, moving toward the hedonism and aestheticism found in the images of advertisements of the time, putting greater emphasis on the body, surfaces, glamour, and youth (Wyatt 1994 126-7). Top Gun can be seen as the perfect mechanism for describing the Reagan era: ${ }^{1}$

It is a film with everything: exciting, well-filmed, aerial sequences, an impressive array of the navy's latest jet aircraft, attractive cast, a powerful rock and roll soundtrack and all the glamour of the world of the elite fighter pilot [...] [I]t is also an intensely patriotic film which celebrates the skill and devotion of navy fliers and American technology. (Paris 1995, 95)

At the same time, in his films Scott recalls the radical changes following the fall of the Berlin Wall, a nation where the enemy becomes more and more undefined and the danger seems to lie in the excessive force of the only remaining world superpower. This society, one of surveillance, constant checks and exasperating technology that might turn against free citizens, is well represented by Scott in several films of the 1990s and early 2000s (Crimson Tide, 1995; Enemy of the State, 1998; Spy Game, 2001). The obsession with success and visibility at all costs in a society exposed to increasing media coverage is rendered in Scott's 'sporty' films such as Days of Thunder (1990) and The Fan (1996), but also in Domino (2005). Déjà Vu (2006) and The Taking of Pelham 123 (2009), with their explicit terrorist threats, are two explicitly post-9/11 films. Finally, Unstoppable (2010) belongs to the Obama era, characterised by its interracial and interclass heroes who unite to face the threat coming from a corporate decision which threatens the rights of workers and citizens. It provides us not with a lone hero, but with a group of humble characters of sound convictions and solid social bonds.

\section{Postmodern, pseudo-modern, metamodern, digimodern}

Alongside this socio-political front, among Scott's films there is one that is merely formal and aesthetic. His films are epigonal, ${ }^{2}$ never defining a genre or movement but interpreting it to the best of their prerogatives. Yet they almost always reference a genre, a movement or a cultural context jointly with its domineering rise. Loving Memory, with its rhythms and formal mannerisms, is close to the atmospheres of the late 1960s 'auteur' European cinemathe evocation of Antonioni's landscapes for example - containing, at the same time, reflections on the refusal of war, new political and social traumas (the British New Wave), memories and biographies (Bill Douglas). 
If, with The Hunger, Scott opened a new elaboration of the vampire figure which has seen numerous variations in subsequent years, Scott also represented the controversial new formalist wave of commercial American films (born from the experience in advertisement of English directors such as Adrian Lyne, Alan Parker, Hugh Hudson, and Ridley Scott). With Top Gun and Days of Thunder, Scott became a significant interpreter of 1980s blockbuster muscular action films, while with Beverly Hills Cop II (1987) and The Last Boy Scout (1991) he made major contributions to the success of the buddy movie. ${ }^{3}$ Even in his last mannerist phase, Scott's films were never off centre or an end in and of themselves. They always seemed to grasp something of the main aesthetic currents which prevailed in the 1990s and 2000 s, abandoning the postmodern to express Scott's alignment to post-postmodernism in the three lines of pseudomodernism, metamodernism and digimodernism (see Vermeulen and van den Akker 2010; and Kirby 2006 and 2009).

True Romance (1993) and Domino distil Quentin Tarantino's postmodern style: in the first case the style is purified by the deconstruction of its time sequences and formal stills; in the second case, on the contrary, it is exasperated in the visual frenzy, its passion for exteriority and images often taken to the limit of visibility. Domino, in this sense, together with Man on Fire (2004), seems to have surpassed postmodernism in accordance with popular culture of the new millennium, moving toward avant pop and remix aesthetics, with audio-visual material linked to the appearance of new technologies being one of the main forms of digimodernism. ${ }^{4}$ Moreover, Domino can be read as a pseudo-modernist film in accordance with Allan Kirby's definition, being a film which stages or becomes essential to completing the text; the theoretical possibility to intervene through the media reality of the user which leads the user into a trance or autistic inaction (Kirby here is referring to Big Brother as well as the films of documentarian Michael Moore). Even though the user has the impression they are taking part in the text, or perhaps because they are actually doing so, they are introduced into a mechanism of reiterating the ludic which takes them away far from the real world to identify the user and text:

In place of the neurosis of modernism and the narcissism of postmodernism, pseudo-modernism takes the world away, by creating a new weightless nowhere of silent autism. You click, you punch the keys, you are 'involved', engulfed, deciding. You are the text, there is no-one else, no 'author'; there is nowhere else, no other time or place. (Kirby 2009; italics in original)

Kirby also speaks of anxiety, paranoia and a new primitiveness following the events of 9/11, which substitute irony and postmodern disenchantment. In opposition to postmodern characters, new protagonists are incapable of 'distrust in the Great Narrative'. The last of Scott's works (from Déjà Vu to Unstoppable) can be matched to such a vision. Perhaps even more so, Scott's last films can be matched to the variable post-postmodern of metamodernism, where we can find the following:

Ontologically, metamodernism oscillates between the modern and the postmodern. It oscillates between a modern enthusiasm and a postmodern irony, between hope and melancholy between naivety and knowingness, empathy and apathy, unity and plurality, totality and fragmentation, purity and ambiguity. [...] They are each at once modern and postmodern and neither of them. (Vermeulen and van den Akker 2010, 5-6) 
This continual repositioning between hope and skepticism, seriousness and irony, knowingness and ingenuousness, structure and deconstruction, seems to belong to Scott's last films which give us the feeling that we are listening in on certain essential contemporary plots before they are returned back to us in a more toned down form. Scott's films grasp the moment, the essential political and cultural events of contemporary relevance, and they are always coherent in terms of the socio-political dimensions being discussed at the time of their release. Nonetheless, the issues his films discuss are often told better elsewhere, in a way more emblematic of the spirit of the time or more penetrating into the collective imagination. The issues for which Scott becomes a spokesman are frequently better represented by the work of other directors, writers and artists. However, what it is so specific to this director is the capacity to mimic and adhere to different cultural and socio-political variables: in other words, his mimetic approach.

The attitude to associate himself with contemporaneity, changing the parameters of reference over time so as to better mirror different cultural climates as they appear, continues through the whole span of Scott's career and becomes one of his main characteristics. In a certain way Scott seems to be metamodern in essence. He succeeds in being both profoundly European (in his early attempts) and profoundly American, Tarantinian and anti-classical, just as he is also perfectly consistent with Hollywood blockbuster rules: modern in Europe and postmodern in America; postmodern and post-postmodern; left-wing and right-wing; Reaganite and Obamian. He is totally distracted by the social issues as he is totally immersed in them, and deeply involved in the definition of exclusively personal parables. At the same time he is driven to define plots and events which deal with the socio-political destiny of America and the rest of the world, warmonger and peacemaker, in love with the reason of State, but he is also capable of understanding the reasons of the individual or a small community (Spy Game, Man on Fire, Unstoppable). By taking on these positions he is never inconsistent with his own contemporaneity expressed through aesthetics or through socialpolitics. Returning to the quotation from Kirby about metamodernism, it is notable that Scott's films always show some visions or narrations of the future, even if they are recognized as problematic.

The last set of Scott's films are also metalinguistic and metamodern in the proper sense of the words, that is to suggest that, while telling a story, they are a reflection on the functions of the new media and of new visual technologies. Those new techniques propose a 'total visibility' and a space of complete control on the mankind. The cinematographic apparatus is a section of these technological devices: to meditate on these tools and be part of them is a metalinguistic practice, and even an invitation to develop a critical vision. Déjà $V u$ and Enemy of the State are emblematic movies in this sense. We can ascribe the idea of contemporaneity - defined as a period of technology, its supremacy on the medial apparatus and, consequently, on social life - to the third category of post-postmodernism that we saw as active in Scott's films, described by Alan Kirby as digimodernism. Digimodernism is a reworked version of pseudomodernism which emphasizes digital dimensions and the new medial configurations that deploy them (from the internet to video games). This new modernism transforms the production and use of media in a radical way, subjecting them even more clearly to the consequences already theorized by Kirby for pseudomodernism (loss of strong authorship, interactivity, collaboration of users in the production process). This digimodernist stage seems to have peculiarities in common with other medial features of 
modernity, labelled in different ways elsewhere: software culture, transmedia storytelling; collaborative and user-centred or UGC era (see Jenkins 2003 and 2006); remix or mash up cultures; relocation of analogic media (cinema in particular) on digital platforms, often through private access (see Casetti 2009a, 2009b, 2011a and 2011b). Scott considers the analysis of new media fields - which is one of the main points of the digimodernism - to be not only an apologetic procedure. Instead, it should also be addressed in order to reveal the contradictions of the technology. This inclination to the metalinguistic theorization on media is central to understanding a more general disposition of reflecting on the modern trends of the director. We saw that, in the final part of his career, Scott approached theories that furthered postmodernism through the configurations of digimodernism, metamodernism, and pseudomodernism. Nevertheless, among these forms, metamodernism seems to be the configuration that acts as a meeting point with Scott's previous career, while also making his original trends in style and content functional to an overall project of reflection on the configurations of contemporaneity.

\section{Déjà $V u$ and postmodernism: time lines and possible worlds}

Déjà $V u$ is an emblematic film in relation to these arguments. The film deals with contemporaneity by putting on stage the society and culture of the period in which the film was made. The film can be defined as postmodern for some of its formal and thematic choices, but it also approaches the hypotheses of outdating postmodernism itself. It is a film consistent with Scott's other works while simultaneously clearly presenting new traits. It portrays, for example, an usual theme for Scott, the one of the relationship between an older protective figure (having a fatherly appearance) and a younger one who, due to his young age, comes across both through their vices and virtues (enthusiasm and joie de vivre as well as the excessive recklessness which follows). However, this film is the only one to entail the theme of heterosexual desire, consequently leading to a distortion of desire in the form of perversion resulting in a necrophilic theme that pervades the whole film. ${ }^{5}$ Moreover, there are hints of some of Scott's formal outbreaks found in previous films, most notably an editing style which nullifies the perceptible and the immediate. In those films there is an active iconic overlapping, which makes the image less intelligible due to the overabundance of information the speed at which it is presented.

Scott reaches a level of formal experimentation of similar reticence concerning the full meaning of the picture. In his two previous films, the 'too full' or excessive amount of data contained in a sequence create a paradox of unintelligibility of the image in which it is difficult to select what is really important, and the message cannot be grasped due to the speed at which it is presented. The same ambiguity and elusiveness is attained in Déjà $V u$ through more subtle techniques, such as elusive and circumstantial shots:

If the film lacks the bag of tricks upended into Scott's previous film, it contains more standard setups of the same outcomes: this is a film of glimpses, splitsecond looks at a license plate or a figure in the distance who may or may not be watching. (Cole 2011)

The most relevant dimension that Scott uses to auscultate contemporaneity is, in this case, time: a non-linear time, subject to landslides and revolutions, typical of postmodern films. Time in Déjà $V u$ is a 'timequake' (Autelitano 2006). 
The film tells the story of Doug Carlin (Denzel Washington), an A.T.F. agent who is involved in an investigation after the explosion of a bomb on a boat in New Orleans which caused over 500 deaths. A team of scientists and investigators use a new kind of software controlled by the government called 'Snow White', which enables them to see, via satellite, what happens in the target area about four days beforehand. A specific instant can be revisited, any chosen detail can be observed, but it cannot be reproduced a second time. Consequently, it is essential to know precisely what needs to be observed in order for the analysis to be useful. Carlin discovers that the key to the matter is Claire Kuchever (Paula Patton), a woman found dead in the river just after the explosion. He instinctively guesses she did not die in the attack.

Carlin decides to have her last few days followed by the satellite system of surveillance. Carlin perceives that the woman is aware that she is being scrutinized. By pushing a laser pen through the 'Snow White' screen, it stimulates a reaction in the woman under observation, and so he realizes that the software does not only carry out mere recordings of what has happened but it is possible to intervene in events. Carlin finds out from a colleague on the investigation that the machine is not simply a system of surveillance, but is an instrument that puts in contact two points in time, present and past, and by turning the time cursor toward himself he creates an Einstein-Rosen bridge (the chance to link one point in the universe to another exceeding the speed of light). Thanks to 'Snow White', the terrorist responsible for the attack is caught (an American warmonger frustrated because his application for enrolment in the US Armed Forces was turned down). Carlin, however, at this point able to actually intervene in the past, wants to prevent any crime that would be committed in the near future but is opposed by some of the top members of his investigation team, some of whom distrust the possibility of modifying past events. Nevertheless, one of the scientists reports that the traditional vision of time, which considers the past-future flux to be linear like the flow of a river, can be diverted creating an alternative line. On one side 'faith', on the other the theory of possible ramifications in co-present time lines with consequential parallel developments and alternative worlds. Applying sufficient energy to the time cursor point enables them to divert the flow, convincing Carlin and one of the scientists to attempt a human journey in time. Carlin is catapulted into the past and he is successful in stopping Claire from dying when the boat explodes, but he dies in the process. Claire, however, takes comfort in meeting Carlin's alter ego in the new parallel reality, formed after the travel in time of the Carlin who lived in the first temporal line. This Carlin is not the one coming from the future so he is, in a way, still alive. We don't know whether the original time line has disappeared or not. Only the past observed on 'Snow White' is present, thus becoming the only 'reality'. What counts is that in one of the time ramifications Claire and Carlin, as well as the passengers on the steamboat, are still alive.

One of the explicit questions in Déjà $V u$ is the assumption of a non-linear time. The film can be classified well within the wide genre of science fiction. Nevertheless, although it deals with scarcely credible issues, on the surface - just like all time travel narratives - it has nothing to do with the 'fantastic' in the metaphysical sense. Time, as it is portrayed in the film, is not 'incredible'. Time in Déjà Vu is of Einstein's conception, potentially reversible, retractable and re-buildable. References to physics when dealing with time distortion are explicit (the Einstein-Rosen bridge, the speculation about the velocity of light, Wheeler's experiments, and any eventual connected paradoxes in the journey) and act as guides for the user of the text. 
One of the questions on which we are spontaneously expected to reflect when reading Alice Autelitano's work on temporality in postmodern cinema concerns the difference between the anachrony on a single time line and the anachrony that enables the multiplication of time lines. The multiplication of time cannot also result in the multiplication of space. Autelitano highlights the multilevel construction - the co-presence of several possible worlds, each one developing its own narrative line - that is certainly a distinctive postmodern element. In fact, Scott's film, despite portraying apparently one temporal flux in which the past and the future converge in a single point or in which past reality anticipates the cause of what happens in the future, actually proposes a different scenario. A homogenous linear time arrow schedules that what happens in the past inevitably modifies what happens in the future: alternative solutions do not exist. Only one past exists and only one future according to the necessary sequence. Back to the Future (1985) or Twelve Monkeys (1995), two films that present time travel in a similar fashion to Déjà $V u$, are examples of different types of temporality as opposed to Scott's film. If, in Back to the Future, every change that Marty McFly (Michael J. Fox) undergoes in the past reverberates on the future, changing it (there is only one future in a linear time cursor - the photos change giving testimony to consequential future variations due to what happened in the past), in Twelve Monkeys, on the contrary, whatever action James Cole (Bruce Willis) performs when he is on his journey into the past, the future will not be able to reproduce itself as effectively as it did when he first set off - it is an unbreakable loop; there is only one past, one future, and one linear and consequential time cursor (Autelitano 2006, 94-98).

Déjà $V u$, as previously stated, presents a situation not comparable to the ones previously mentioned. Carlin, after experiencing the epiphany of being able to intervene in the past and influence it, tries to convince the team investigating the terrorist action that they can send an object into the past to try and substantially modify events that have already taken place. Carlin undergoes a barrage of objections which assume the immutability of the past; the objections are placed not only on a scientific level but also on a spiritual one. When Carlin hints that there is not just science, Denny (Adam Goldberg) replies, 'you can't modify the past because God has already decided'. Moreover, the only female agent/scientist in the group, Shanti (Erika Alexander), opposes a potential alternative interpretation, the "theory of a ramified universe'. Time is a linear flow from A (Past) to B (Future) comparable to a river where a sufficient spurt of energy placed inside this flow can activate a forking that changes it, diverting it to a specific point. Two worlds/branches are created (the source of a temporal river that before was an estuary and now becomes a forked delta), each one following and existing on its own. The original branch 'could continue in a parallel way to the new branch or it could also cease to exist', says Shanti (see Figure 1). 


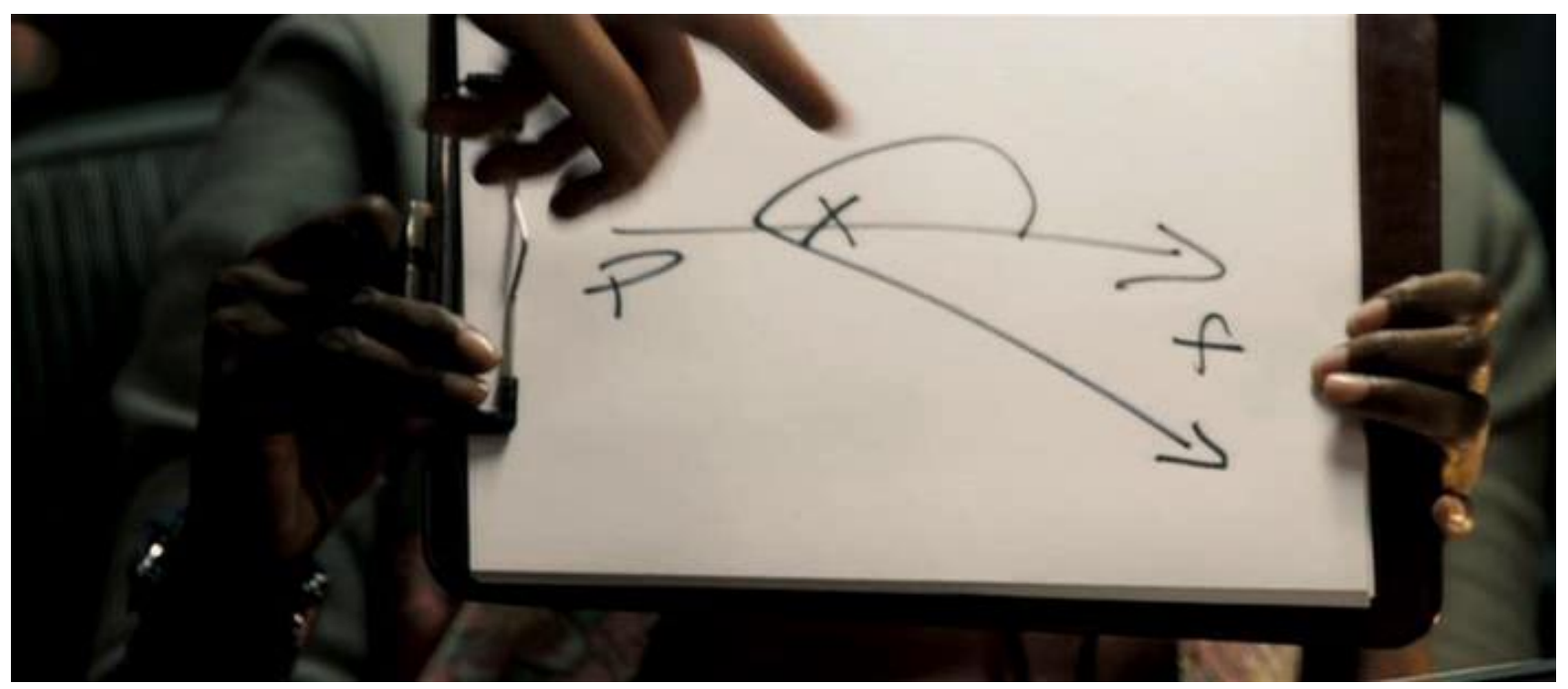

Figure 1: The 'theory of the ramified universe', explained by Shanti

The film continues with Carlin's journey into the past and his changing of it through his actions, confirming the theory to be correct. Scott's film is the first not to exclusively present a theory of time travel but an interpretive postmodern conflict between potentially equally valid theories (science and faith, the theory of ramified worlds and the theory of a single world with an immutable time flow). Equally postmodern is the fact that the film does not provide any clear answers. ${ }^{6}$

We know nothing of what happens to the original branch, whether it continues to exist or simply disappears. What we do know is that a new branch is born parallel to the original one, and that what happens after the changes in the past take place is an expansion and pluralisation of worlds (and times). As Thomas Elsaesser has argued in the case of 'the media worlds we inhabit', Déjà $V u$ permits at this juncture 'different spaces to coexist and different times to overlap' instead of relying on the 'single diegesis of classical cinema' (Elsaesser 2006, 216-17). The parallel reality is more than a representation within the contours of the diegesis; it is a second possible world, a second diegetic reality whose distinguishing feature is its setting four-plus days in the past. It is not so much that it overlaps but that it exists in parallel to the world occupied by Carlin and his Bureau colleagues (Anderson 2006).

Although Déjà $V u$ demonstrates all the features of a film with a 'forking-path narrative' —one rooted in Hollywood classical cinema to shape the narrative structures, as extensively demonstrated by Bordwell (2002) — we can nevertheless recognize in it something different. It is what Branigan, in an essay that recalls and re-elaborates Bordwell's proposition, describes as 'a more radical, subjectivized form of forking paths that depict altered, ulterior, and alternative states of awareness' (Branigan 2002, 107-8). This is the case in Scott's film: an extreme forking-paths strategy is active in Déjà $V u$. Branigan notes that in Bordwell's essay:

explicit forking-path narratives are often rather modest in their ambitions, perhaps because we can hold only a small number of alternatives in conscious awareness and classical narrative strives for a certain economy of thought: 'at any moment we can imagine two or three alternative chains of events... but not twenty or sixty, 
let alone an infinite number. (Branigan 2002, 109)

On the contrary, during the fruition of Scott's film the viewer is free to make their own inferences and to develop the largest possible number of hypotheses on the possible worlds. Although it is carried out only once in the film, such expansion is potentially reproducible and worlds can proceed in parallel, through interventions that fork the past are potentially infinite. Scott, compared to the most extreme experimentalism, holds back with his usual attitude of mediation in presenting a more classical structure, but the theoretical background of the fictional world created in his film is one of a potentially infinite world in constant expansion through alternative branches of parallel worlds. If the narration, which here is traditional and linear, was taken to extreme consequences, or indeed if it described more than one of the temporal breakages between the worlds in parallel, we would find ourselves faced with a combinative novel in which infinite worlds would match each other and would get lost in references to the infinite chain. In short, we would be inside a story of Borges or Calvino. Therefore, according to metamodernism, Déjù $V u$ is neither a traditional film in which forking-path narratives lead to a limited series of alternatives, nor a postmodern film in which all the branches have the same importance: the final draft proposed by the director is the one 'more (and morally) desirable' even if it may not be real.

Furthermore the film, in structuring the relationship with its audience through its forking paths, shows one of the main features of the pseudomodernist dimension:

pseudo-modernism makes the individual's action the necessary condition of the cultural product. Pseudo-modernism includes all television or radio programmes or parts of programmes, all 'texts', whose content and dynamics are invented or directed by the participating viewer or listener. (Kirby 2006; italics in original)

Déjà $V u$ postulates that viewers should imagine the possible futures presumed by the forking paths narrative as 'nearly true' (Branigan 2002, 110). Even in this strict interaction with spectators and their reactions to the films, Scott is revealed to be pseudomodernist.

\section{Spatialised time}

The mechanism of the proliferation of parallel worlds is not the only one to deconstruct a linear and conventional temporality in Scott's films. One of the prerogatives of contemporary temporality is the spatialisation of time. Time contracts, included in a flow that establishes hyperkinetic and immediate connection with multiple points. Globalisation and digitalisation allow us, through a speed that tends toward the quickness of transport and immaterial means of communication (flows of digital data), to reduce distances between different places, almost to the point of compressing them and making them co-present. This means that the time required to cover spatial distances is substantially reduced. Everything is co-present, and therefore the time required to bridge distances is shortened almost to the point of extinction, translating the time/space relation into a constant present corresponding to the instant (see Autelitano 2006, 43-44). Rather than expanding in a flow of subsequent instants, time extends on a table of co-present instants.

When Carlin carries out his investigation using 'Snow White', some of the shots frame him and Claire one in front of the other, showing the intensity of a rhetorical figure within a close- 
up. She cannot see him and the two bodies are mediated by the screen, but they 'perceive' each other: they establish a relationship which is somewhat sentimental and emotional. They are within the same space in a temporal bubble, in which Carlin's world is Claire's future and Claire's world is Carlin's past. In fact, in an Einsteinian way, present or past are dependent on the system in which the observer is placed. However, Carlin and Claire act together: Carlin projects a laser into Claire's reality and she perceives it. This past/future relationship is, therefore, also a 'present' for both of them, each one in relation to the other. It is a present that exists only as an instant and does not assume other successive or previous time (when past and future take place 'now', they become present and have no logical reason to subsist). This consideration is not far from some of the characteristics of contemporary time described by Autelitano: reducing all time (indeed the past-present-future flow) to a continuous present and cancelling, thanks to the acceleration of the contemporary world, the space-time distances in the instant and co-presence.

A further spatialisation of time intervenes in the relationship between the viewer and the film and, after the time jump, in the one between Carlin and the world he sees in the past while it is taking place for the first time but is a repetition for him. Indeed, the viewer and Carlin, observing the same action which takes place two times at a determined moment, are encouraged to watch it again in order to identify the details which take on new meanings in relation to the first vision. Thus time becomes a function of space, expanding and determining what happens in space. Time almost becomes 'concrete': guaranteeing through itself 'power' to the eye, it changes the space according to the eye of the observer. As it changes, the object, which takes on a new meaning at a second glance, is nothing more than 'spatialised time'.

The titular déjà vu envelops both the audience and the characters as we all see each image at least twice, in the present and past, and usually more often than that, and each new glimpse challenges the viewer to recall a past observation and to alter the perception of it with new information. (Cole 2011)

\section{Paranoia and time beyond the postmodern: television exorcisms and political fiction}

A further possibility inherent to the issue of time in Déjà $V u$ seems to lead us beyond postmodernism. One of the prerogatives that seem to belong to post-postmodernism is the return to 'History'. Roy Menarini points out how the 'great season of Hollywood timequakes', stretching from the 1990s to 2001, 'was about a self reflexive tendency internal to the postmodern season between film and viewer, in a context particularly suitable for enjoyment (jouissance) because of the ludicity of the text' (Menarini 2010, 54). This entails the attention focused on linguistic, formal and narrative questions, rather than on political, social or historical issues. According to Menarini, however, something has changed in the last few years which must also be linked to socio-political issues, not only within aesthetics:

What changes from a certain point onwards is precisely the distinction between the images and the world. It is difficult, no matter how rhetorical it may sound, to attribute to $11^{\text {th }}$ September and the following international wars, a decisive role in this transformation. [...] If then, it is true that American post $11^{\text {th }}$ September cinema has rediscovered its true relationship with the world or indeed has pumped in [...] forms of allegorical intensifications and ideological-political interpretations to the history $[\ldots]$ why then should the 'play' on time have been 
taken up by television series? Simple answer. Because it is no longer a game. (Menarini 2010, 54)

The deconstruction and playing with time are inherited in particular from television series that elaborate on those settings with new meanings. This is a society that makes objects of anxiety, 'presentification' and paranoia, brought to us in audiovisual form (see Huber and Peranson 2007). For Menarini the reason for this change from a non-linear temporality to an alternative structure lies in the possibility of representing, in an exasperated manner, not only the anxiety of contemporary society but also the exorcism of them, which suggests there could be a possible future. But it also lies in the proposals of possible rearrangements within American society itself that these television series offer (see Menarini 2010, 55). According to Menarini, cinema was seen as one of the main vehicles of propaganda for the Western vision of society which considered itself as satisfied and without further needs, devoted to transmitting its values to the rest of the world. For this reason cinema has been criticised for an 'iconic complicity with regard to the terrorist attacks, giving way to self censorship in the ludic narrative' and this ludic approach was transferred to the television series (Menarini, 2010, 55).

These considerations are well suited to the temporal strategies and contents of Déjà $V u$ which, showing the capability for adhering to practises belonging to the post-postmodern period, such as transmedial proliferations. The film proposes a metaphoric and alternative version of American history from 2001 onwards. There are clear references to terrorist attacks aside from 9/11 including, most clearly, the Oklahoma City bombing of $1995 .^{8}$ The film could also propose a strategy of 'normalisation' following the events in New Orleans caused by the Hurricane Katrina, as explained by Briallen Hopper in his essay on the film. Hopper speaks of a conservatory and normalising strategy for the film resulting from the space-time collocation and the film's use of time strategies (Hopper 2011, 277-92). New Orleans has the generic look of most American cities, and the choice of setting is a consequence of production necessity on one side and a certain opportunism on the other. ${ }^{9}$ Most notable in this regard is the systematic removal of flooded areas within the film (the French quarter is not covered by the panoptic gaze of 'Snow White'), the apparent regularity and continuation of communal life (no black-outs or interruptions of the water supply or similar problems that the city had to endure), and the total exclusion of representation of social tensions linked to these hardships. New Orleans becomes not so much an actual reality but a future projection, a parallel world: the New Orleans of Déjà $V u$ is not what the city has been nor was during the few years following after the hurricane, but what it is expected to be like in the near future.

A tidy and liveable city, made safe thanks to continual surveillance by government officers thanks to the power of technology, this depiction of New Orleans implies that giving up a lot of personal freedom and privacy will allow the government to prevent every sort of crime. The city thus loses its own specific identity: it is no different from the America of a control society/ police state created by George W. Bush post-9/11. Indeed, this utopian version of society is the one that the Bush administration would have liked to obtain, had it reached absolute success in its strategies of exaggerated control. Scott seems to build this alternative temporal reality: an anachrony, an alternate history and political fiction. Scott changes the outcome of the effectively computed story so as to propose an alternative version in which 
traumas are removed and the actions of emergency management of the Bush administration after the Hurricane Katrina are not questioned. According to Hopper, to represent time travel in a film where the city appears post-Katrina but seems identical to the city before the event denies the sensation of irreparable human and cultural loss; the responsibility regarding the rescue work and the detachment from survivors is hidden, all of which is made clear in the photos which show the devastation with great detachment on the part of Air Force One (Hopper 2011, 289-290). An impression is created, through a parallel and distorted world and through a temporal present/past comparison enables by time travel, that nothing could be changed in the Bush strategy and that the loss never really came about. As for what happened when faced with threats of crises - internal and external, ecological and military - there is indeed the birth of an anachronistic alternative reality in which America, under the technological eye of the government, becomes completely harmonious, homogenous and totally safe. Scott thus shows himself to be commenting on the period and practises a symbolic mimesis of Bush's presidency (see Marin-Guzman 2007).

Therefore, as stated at the start of this essay, there are many identifiable characteristics in Scott's film that suggest its framing as among those works capable of bypassing postmodernity. Where can we find this circumvention? The answer lies in the construction of non-linear time, but not purely for fun as in postmodern works; it lies in imagining parallel and virtually infinite worlds all containing concreteness and realism, not only combinatory in nature; it lies in a register that is never merely ironic nor exclusively serious or staid; it lies in a passion for the subject being narrated and a credibility in one's own work; it lies in the mixing of classicism and anti-classicism, art and politics, social issues and aesthetics; it lies in the presence of complex narrative development not detached from accessibility for mass viewing; it lies in the subtle linguistic experimentation carried out from the inside (a fleeting glance); it lies in the unclear or non-immediate identification of the genre of film (it is a genre part-way between political thriller, pure science fiction or fantasy, action film and detective story); it lies in not being without references to current affairs and building potential anachronisms and possible worlds; it lies in the re-launching of transmedial themes, forms and implications of other medial forms such as television series. Hopefully it is clear now that such characteristics respond to what has previously been illustrated as the bypassing of postmodern in the form of pseudomodernity, digimodernity or metamodernity.

In Italy, an attempt was made to systemise the connotations of what is beyond postmodernity through the New Italian Epic movement and its manifesto (Ming 2009). This is not the place to discuss and illustrate the main features of this movement, but nevertheless its program, starting from its name, collects and reshapes on a more sophisticated level the needs and requests of metamodernism and pseudo/digi-modernism The adjective 'epic' - entailing a concentration on historical, legendary and, at times, metaphysical elements within a background of conflict, catastrophe, and social formations on the point of collapse that define a historical segment - seem to be valid in relation to Déjà $V u$. Moreover, it confirms, beyond all the critical downsizing that has followed, its value similar to ones found in other Scott films as 'minor' epochal compendia. This characteristic of summarising an era is achieved expressly through with the temporal strategies at work in the film.

\section{Conclusion}

Tony Scott can be seen as a director who has always tried to capture and reproduce 
contemporary cultural waves in ways understandable to wider audiences. Within this strategy, in his last films and Déjà $V u$ in particular, Scott decides, to approach postpostmodernism. Scott is able to adopt both canonical and non-canonical traits according to the needs of contemporary cultural contexts. His stylistic versatility seems, when analysed in the context of his filmography, to be self-aware and exhibits a real metalinguistic aptitude. Scott's ability to illustrate contemporaneity - always being up-to-date with the most advanced social and aesthetics theories - is a method for reflecting on modernity while representing it: this is precisely the tactic of metamodernism. Déjà $V u$ also shows other distinctive characteristics of metamodernism, and likewise those of pseudo- and digimodernism: the attention to audience feedback; the creation of a plot based on anxiety and paranoia rather than on irony and disenchantment; the attraction, mixed with a certain fear, for technological devices (medial ones in particular); the production of potentially unlimited divergent temporal lines, forking paths and alternative worlds, even admitting that they might never materialize. In all these elements, Déjà $V u$ reveals itself to be consistent with the zeitgeist of the epoch in which it was realized in both aesthetic terms, but also in political and social ones, confirming Scott's ability to astutely reflecting contemporaneity.

\footnotetext{
${ }^{1}$ For more detail and contextualisation of the ties between Reagan ideology and militarism in Top Gun see Cockburn 1987, 163-72; and Suid 2002, 499-501.

${ }^{2}$ Here the term 'epigonal' is used in a rather metaphoric way. It does not mean that Scott's films are merely 'imitative' of a genre or style, but that they often use some traits of particular genres or styles particularly popular within certain epochs, to develop the personal point of view of the director. Those films are never the fullest expressions of those styles or genres to which they belong, nor have they launched new aesthetic trends, but they nevertheless succeed in providing the atmosphere of a particular time.

${ }^{3}$ These films are comedies in which the action is based on a couple of characters forced, often against their will, to team up to tackle a common goal. Notable examples include 48 HRS. (1982), Lethal Weapon (1987), Midnight Run (1988), See No Evil, Hear No Evil (1989), Bird on a Wire (1990), and Men in Black (1997). See Gates 2003, 73-75; Altman 1999; and Donalson 2006.

${ }^{4}$ For avant-pop, see Amerika 1993; for remix culture, see Lessing 2009, Manovich 2013, Sovilla-Weiss 2010, and Brett Gaylor's documentary RiP! A Remix Manifesto (2008). David Bordwell, agreeing with this vision of Scott as a digimodernist remix supporter, states: 'Scott takes pleasure in playing up the disparities among the footage, cutting from "direct" presentation of material to mediated images and sounds. In the conspiracy films, the video images seem to be coming from a vast image bank or database that the film is sampling on the fly. Moreover, the constant interruption of one shot by another, seen on computer or news broadcast or spycam, creates a nervous visual narration. In effect, Scott imports the mixed-format collages of [Oliver] Stone's JFK (1991) into the action film' (2013).

${ }^{5}$ The perversion suggested by some plots and images of Scott's movies was noticed by some critics (see, for example, Bevan 2014).

${ }^{6}$ For Alice Autelitano, not providing evaluative criteria of facts whose nature remains uncertain is connected to the strategy of arranging postmodern time $(2006,83)$.

${ }^{7}$ Steen Christiansen (2013) focuses on the particular structure of the co-present present/past in Tony Scott's film to illustrate something that seems to be similar to these considerations.

${ }^{8}$ The terrorist showed in the film is a lonely American sociopath who believes himself to be the only 'real' patriot. He is angry with the U.S. government after being rejected for recruitment by the Army, who believed he was emotionally unstable. Rather than depicting an 'external' terrorist with political or religious positions to defend, the character of Carroll Oerstadt (Jim Caviezel) recalls the Gulf war veteran Timothy McVeigh, who was found guilty of the Oklahoma City bombing. See Roberts 2006.

${ }^{9}$ Originally the film was to be shot in New York and only the explosion sequences were to be shot in New Orleans, the only city who gave permission to do so. After Hurricane Katrina, Scott decided to film the whole film there, discovering it to be a metaphorically dense place at the time. New Orleans and its people actively cooperated in the making of the film, the first to be filmed there after the disaster. The film gave the people's imagination a sense of collective rebirth and liberation (Hopper 2011, 280-281).
} 


\section{References}

Altman, R. (1999) Film/Genre, London: British Film Institute Publishing

Amerika, M. (1993) Avant-Pop Manifesto, [blog], nd. Accessible at http://www.altx.com/manifestos/avant.pop.manifesto.html. Accessed 1 July 2014.

Anderson, M. J. (2009) 'Resurrecting the Rube: Diegesis Formation and Contemporary Trauma in Tony Scott's Déjà Vu (2006)', [blog], 12 November 2010, originally published in Film Criticism, 33(2). Accessible at http://tativille.blogspot.co.uk/2010/11/resurrecting-rube-diegesis-formation.html. Accessed 1 July 2014.

Autelitano, A. (2006) Cronosismi. II tempo nel cinema postmoderno, Udine: Campanotto

Bandirali, L. and Terrone, E. (2013) Filosofia delle serie tv. Dalla scena del crimine al trono di spade, Udine-Milano: Mimesis

Bevan, J. (2014) 'Man on Fire: Tony Scott', BFl.org.uk, 5 February. Accessible at http://www.bfi.org.uk/news-opinion/sight-sound-magazine/features/man-fire-tonyscott. Accessed 1 July 2014.

Bordwell, D. (2002), 'Film Futures', SubStance, 31(1), 88-104

--- (2013) 'Tony and Theo', [blog], 3 February. Accessible at

http://www.davidbordwell.net/blog/2013/02/03/tony-and-theo/. Accessed 1 Jul 2014.

Branigan, E. (2002) 'Nearly True: Forking Plots, Forking Interpretations: A Response to David Bordwell's "Film Futures"', Substance, 31(1), 105-14

Carocci, E. (2014) 'Effetto Domino: Tony Scott e I limiti del postclassico', in M.

Gerosa (ed.), II cinema di Tony Scott, Piombino: II Foglio Letterario, pp. 183-195.

Casetti, F. (2009a) 'Filmic Experience', Screen, 50(1), 56-66

--- (2009b) 'Ritorno alla madrepatria. La sala cinematografica in un'era postmediatica', Fata Morgana, 8, 173-88

--- (2011a) 'Cinema Lost and Found: Trajectories of Relocation in Screening the Past', ScreeningthePast.com, 32. Accessible at http://www.screeningthepast.com/2011/11/cinema-lost-and-found-trajectories-ofrelocation/. Accessed 1 July 2014.

--- (2011b) 'Back to the Motherland: The Film Theatre in the Postmedia Age', 
Screen, 52(1), 1-12

Christiansen, S. (2013) 'Texture and Time in Tony Scott's Déjà Vu', conference paper given at 'Texture in Films', University of Saint Andrews, 9 March. Accessible at http://vbn.aau.dk/en/activities/texture-and-time-in-tony-scotts-deja-vu(3712acff-d529404b-ae5e-c29175d29a18).html. Accessed 1 July 2014.

Cockburn, A. (1987) Corruption of Empire: Life Studies and the Regan Era, LondonNew York: Verso

Cole, J. (2011) 'Dèjà Vu', Cinelogue.com, 20 March. Accessible at http://www.cinelogue.com/reviews/deja-vu. Accessed 1 July 2014.

Donalson, M. B. (2006) Masculinity in the Interracial Buddy Film, Jefferson, NC: McFarland

Elsaesser, T. (2006) 'Discipline through Diegesis: The Rube Film between "Attraction" and "Narrative Integration"', in W. Strauven (ed.), The Cinema of Attractions Reloaded, Amsterdam, Amsterdam University Press, pp. 205-23

Gates, P. (2003) 'Buddy film' in B. E. Carrol (ed.), American Masculinities. A Historical Encyclopedia, Thousand Oaks, CA: Sage

Gerosa, M. (2014) 'Tony Scott regista d'azione', in Mario Gerosa (ed.), Il cinema di Tony Scott, Piombino: II Foglio Letterario, pp. 33-49.

Hopper, B. (2011) 'The City that Déjà Vu Forgot: Memory, Mapping and the Americanization of New Orleans', in D. E. Barker and K. McKee (eds), American Cinema and the Southern Imaginary, Athens, GA: University of Georgia Press, pp. 277-292.

Huber, C. and Peranson M. (2007) 'World out of Order: Tony Scott's Vertigo', Cinema-Scope.com, nd. Accessible at http://cinema-scope.com/cinema-scopeonline/world-out-of-order-tony-scotts-vertigo/. Accessed 1 July 2014.

Jenkins, H. (2003) 'Transmedia Storytelling', MIT Technology Review, [online], 15 January. Accessible at http://www.technologyreview.com/news/401760/transmediastorytelling/. Accessed 1 July 2014.

--- (2006) Convergence Culture: Where Old and New Media Collide, New York: New York University Press 
Jeong S. (2012) 'The Apocalyptic Sublime: Hollywood Disaster Films and Donnie Darko' , in T. A. Comer and L. I. Vayo, (eds), Terror and the Cinematic Sublime: Essays on Violence and the Unpresentable in Post-9/11 Films, Jefferson, NC: McFarland, pp. 72-87

Kirby, A. (2006) 'The Death of Postmodernism and Beyond', Philosophy Now, [online], 58. Accessible at http://philosophynow.org/issues/58/The_Death_of_Postmodernism_And_Beyond. Accessed 1 July 2014.

--- (2009) Digimodernism: How New Technologies Dismantle the Postmodern and Reconfigure Our Culture, New York: Continuum, 2009

Lessing, L. (2009) Remix: Making Art and Commerce Thrive in the Hybrid Economy, New York: Penguin

Manovich, L. (2013) Software Takes Command, New York: Bloomsbury Academic

Marin-Guzman, D. (2007), 'The Politics of Déjà Vu', [blog], 20 June. Accessible at http://daveguzman.blogspot.it/2007_06_01_archive.html. Accessed 1 July 2014.

Menarini, R. (2010) 'Il complotto del tempo. Stravolgimenti cronologici dal cinema alla televisione dopo l'11 Settembre 2001', Cinergie, 20, 54-56. Accessible at http://www.cinergie.it/CINERGIE_ARCHIVIO_WEB/Cinergie20_web.pdf. Accessed 1 July 2014.

Paris, M. (1995) From the Wright Brothers to Top Gun: Aviation, Nationalism and Popular Cinema, Manchester: Manchester University Press

Roberts, S. (2006) 'Tony Scott Interview, Director, Déjà Vu', MoviesOnline.com, nd. Accessible at http://www.moviesonline.ca/movienews_10491.html. Accessed 1 July 2014.

Sovilla-Weiss, S. (2010) (ed.), Mash Up Culture, Wien-New York: Springer Verlag

Suid, L. H. (2002) Guts \& Glory: The Making of American Military Image, Lexington: The University Press of Kentucky

van den Akker, R. (2010) 'What is Metamodernism', [blog], 15 July. Accessible at http://www.metamodernism.com/2010/07/15/what-is-metamodernism. Accessed 1 July 2014. 
Vermeulen, T. and van den Akker, R. (2010) 'Notes on Metamodernism', Journal of Aesthetics and Culture, 2. Accessible at

http://aestheticsandculture.net/index.php/jac/article/view/5677/6304. Accessed 1 July 2014.

Wu Ming (2009) New Italian Epic. Letteratura, sguardo obliquo, ritorno al futuro, Torino: Einaudi

Wyatt, J. (1994) High Concept: Movies and Marketing in Hollywood, Austin: The University of Texas Press

ZC (2007) 'The Zeitgeist Finds Tony Scott', [blog], 29 January. Accessible at http://elusivelucidity.blogspot.co.uk/2007/01/zeitgeist-finds-tony-scott.html. Accessed 1 July 2014. 